\title{
Multifunctional protein particles with dual analytical channels for colorimetric enzymatic bioassays and fluorescent immunoassays
}

Lai Kwok Kei, Renneberg Reinhard and Mak Wing Cheung

\section{Post Print}

N.B.: When citing this work, cite the original article.

Original Publication:

Lai Kwok Kei, Renneberg Reinhard and Mak Wing Cheung, Multifunctional protein particles with dual analytical channels for colorimetric enzymatic bioassays and fluorescent immunoassays, 2012, Biosensors \& bioelectronics, (32), 1, 169-176.

http://dx.doi.org/10.1016/j.bios.2011.11.051

Copyright: Elsevier http://www.elsevier.com/

Postprint available at: Linköping University Electronic Press http://urn.kb.se/resolve?urn=urn:nbn:se:liu:diva-86354 
Multifunctional Protein Particles with Dual Analytical Channels for Colorimetric Enzymatic Bioassays and Fluorescent Immunoassays

\author{
Authors: Kwok Kei Lai ${ }^{\text {a }}$, Reinhard Renneberg ${ }^{\text {a }}$, Wing Cheung Mak ${ }^{\text {a,b* }}$ \\ ${ }^{a}$ Department of Chemistry, Hong Kong University of Science and Technology, Clear \\ Water Bay, Hong Kong, P.R. China \\ ${ }^{\mathrm{b}}$ Nano and Advanced Materials Institute Limited, Hong Kong University of Science \\ and Technology, Clear Water Bay, Hong Kong, P.R. China \\ * Corresponding author at: Hong Kong University of Science and Technology, \\ Department of Chemistry, Clear Water Bay, Hong Kong, P.R. China \\ Tel.: +852 23587410; fax: +852 23581594 \\ E-mail address: chmartin@ust.hk
}

Keywords: protein microparticles, encapsulation, enzymatic assays, immunoassays, colorimetric detection, fluorescence detection

\begin{abstract}
Advanced multifunctional protein particles encapsulated enzymes and antibodies were developed for enzymatic bioassays and immunoassays with colorimetric and fluorescent channels. A colorimetric channel based on colour-substrate precipitation was assigned for enzymatic bioassays for the measurement of hydrogen peroxide with the lowest detectable concentration of $10 \mu \mathrm{M}$. A fluorescent channel based on fluorescent labeled antibodies was assigned for immunoassays for the measurement of mouse immunoglobulin $\mathrm{G}(\mathrm{M} \mathrm{IgG})$ with the lowest detectable concentration of 1.25 $\mu \mathrm{g} \mathrm{L}^{-1}$. The protein microparticles were fabricated with a template-assisted self-assembly technique termed "Protein Activation Spontaneous Self-assemble" (PASS). The multifunctional protein particles prepared with the PASS method have the advantages of high loading of analytical biomolecules, integrated biological functions, porous structure, and more importantly, they are optically transparent and fluorescence inactive. These unique features make our protein particles a new generation of bead-based platforms to perform enzyme bioassays and immunoassays.
\end{abstract}

\title{
1. INTRODUCTION
}

Performing analytical measurements using miniaturized systems, such as microparticles have attracted great interest in various applications such as medical diagnostics (Mak et al., 2005, 2011; Xiang et al., 2011; Zhang et al., 2011) 
environmental monitoring (Kim et al., 2008; Ramon-Azcon et al., 2009), chemical processes (Mak et al., 2008a) and biological system monitoring (Fischer et al., 2009). Using microparticles as bioassay platforms can localize and concentrate the analytes within the microparticles relative to the solution phase and thus can enhance the performance of biotests. In addition, a microparticle immobilizing a bioassay within a small "compartment" allows individual bioassay to be performed within individual microparticle compartment. Tens of thousands of microparticles can be dispersed within a microliter sample solution permitting many parallel measurements to be performed. Microparticles are promising "biosensors" of the future.

In state-of-the-art microparticle-based analytical system, analytical particles exhibiting specific biological functions are constructed by conjugation of antibodies or enzymes onto the surface of polymer particles (e.g. polystyrene PS) using chemical or physical methods (Kasturi et al., 2005; Yang et al., 2001). The PS particles provide a two dimensional platform where bioassays are only performed on the particle surfaces, while the large internal volume of the microparticles is almost wasted. PS particles are useful platforms for surface binding assays (Malmstadt et al., 2004; Verpoorte et al., 2003; Vignali et al., 2000; Yan et al., 2005). However, performing enzymatic bioassays onto PS particle surfaces is difficult. Research has been focused on developing microcapsules encapsulating enzymes in the capsules' interior (Bai et al, 2010; Caruso et al, 2000; Mak et al., 2009; Parthasrathy et al., 1994). Polymeric microcapsules provide a three dimensional platform that allow the localization of generated signals within the inner compartment of the microcapsules. Most of the existing polymeric microcapsules are fabricated by assembling of polyelectrolytes or synthetic polymers into multilayered structure which forming the microcapsule membrane. However, the preparation for such microcapsules are labor intensive and involving tedious procedures (Mak et al., 2008b).

Recently, we have developed a novel technology to fabricate bio-functional protein particles using a new technique termed "Protein Activation Spontaneous Self-assembly" (PASS) (Mak et al., 2010). The PASS method combines the particle fabrication and biomolecule integration processes into a single procedure. In brief, the fabrication of protein microparticles is based on using the internal disulfide bridges within protein molecules as molecular linkers to assemble protein molecules into a microparticle form. The PASS method provides a simple and robust approach to produce protein-based particles with integrated and preserved biological functions. The resulting particles are highly homogeneous and stable. More importantly, they are optically transparent and fluorescence inactive. Various specific biomolecules with different biological functions can be integrated into the protein particles.

In this article, we further demonstrate an innovative concept on using multifunctional 
protein particles prepared by the PASS method for enzymatic bioassays and immunoassays with coloriometric and fluorescence channels. Multifunctional protein particles composed of enzymes and antibodies were fabricated with the PASS method. The porous protein particle provides a three dimensional analytical platform for the performance of bioassays. The large internal volume allows an extremely high loading of biomolecules inside individual protein particle. The porous nature facilitates effective analyte diffusion and provides a cavity for the accumulation of the generated signals. A colorimetric channel based on coloured-substrate precipitation was assigned to the enzymatic bioassay for the detection of hydrogen peroxide and a fluorescence channel based on fluorescence labeled antibodies was assigned to the sandwich immunoassay for the detection of mouse immunoglobulin G (M IgG). In the presence of hydrogen peroxide or $\mathrm{M} \mathrm{IgG}$, the multifunctional protein particles generated only a blue color signal or a fluorescence signal, respectively; while in the presence of both hydrogen peroxide and $\mathrm{M} \operatorname{IgG}$, the multifunctional protein particles generated both the blue color and fluorescence signals (Figure 1). Our results demonstrate the first time in literature the performance of enzymatic and immunoassays within a single particle platform. These findings are the foundation for further development of multifunctional protein analytical particles to a powerful multiplexing method for diagnostics and drug screening.

\section{Preferred position for Figure 1}

\section{MATERIAL AND METHODS}

\subsection{Materials.}

Calcium chloride and sodium carbonate were purchased from Sigma Aldrich. Affinity-purified polyclonal goat anti mouse immunoglobulin $\mathrm{G}$ (Gt $\alpha \mathrm{M} \mathrm{IgG}$ ) and mouse immunoglobulin $\mathrm{G}(\mathrm{M} \mathrm{IgG})$ were purchased from Arista Biologicals Inc. (Allentown, PA, USA). Fluorescence labeled Gt $\alpha \mathrm{M}$ IgG (FITC- Gt $\alpha \mathrm{M} \mathrm{IgG),}$ bovine serum albumin (BSA), dithiothreitol (DTT), 3,3',5,5'-tetramethylbenzidine dihydrochloride (TMB), horseradish peroxidase (HRP) and 2-(N-morpholino)ethanesulfonic acid (MES) were purchased from Sigma. Ethylenediaminetetracetic acid (EDTA) was purchased from Invitrogen. 1-Ethyl-3-[3-dimethylaminopropyl] carbodiimide hydrochloride (EDC) and N-hydroxysulfosuccinimide (Sulfo-NHS) were purchased from Pierce Chemical Company (Rockford, IL, USA). SeramunBlau®prec (without hydrogen peroxide) was purchased from Seramun Diagnostica GmbH (Heidesee, Germany). Hydrogen peroxide $\left(\mathrm{H}_{2} \mathrm{O}_{2}\right)$ was purchased from Honeywell Riedel-de Haën (Seelze, Germany). 


\subsection{Preparation of BSA-peroxidase conjugates.}

A solution mixture containing $960 \mu \mathrm{L}$ BSA solution $\left(2.08 \mathrm{mg} \mathrm{mL}^{-1}\right), 20 \mu \mathrm{L}$ EDC and $20 \mu \mathrm{L}$ NHS in 0.1 M MES buffer pH 6.0 was freshly prepared and incubated for 15 minutes at room temperature to allow the activation of the BSA. Then, $1 \mathrm{~mL} \mathrm{HRP}$

solution ( 770 units $\mathrm{mL}^{-1}$ ) was added to the activated BSA solution mixture and incubated for 2 hours at room temperature. Subsequently, the BSA-HRP conjugates were harvested and concentrated to a final volume of $100 \mu \mathrm{L}$ using a $50 \mathrm{~K}$ Nanosep ${ }^{\circledR}$ centrifugal device (Pall, USA).

\subsection{Preparation of BSA-peroxidase microparticles.}

A solution containing $0.5 \mathrm{~mL}$ calcium chloride $(1 \mathrm{M}), 460 \mu \mathrm{L} \mathrm{BSA}\left(20 \mathrm{mg} \mathrm{mL}^{-1}\right)$ and $40 \mu \mathrm{L}$ BSA-HRP $\left(20 \mathrm{mg} \mathrm{mL}^{-1}\right)$ was rapidly mixed with $1 \mathrm{~mL}$ sodium carbonate $(0.5$ $\mathrm{M})$ and keep stirring for 30 seconds to produce BSA/BSA-peroxidase loaded $\mathrm{CaCO}_{3}$ microparticles. The BSA/BSA-peroxidase loaded $\mathrm{CaCO}_{3}$ microparticles were washed five times by centrifugation (2000 r.p.m., 2 minutes) and re-dispersion cycles. The resulting BSA/BSA-HRP-loaded $\mathrm{CaCO}_{3}$ microparticles were incubated with DTT solutions with a concentrations of $2 \mathrm{mM}$ at $\mathrm{pH} 7.5$ or glutaraldehyde $(2 \% \mathrm{v} / \mathrm{v})$ for 30 minutes. Subsequently, the BSA/BSA-HRP-loaded $\mathrm{CaCO}_{3}$ microparticles were washed five times by repeated centrifugation at 4,000 r.p.m. for 2 minutes to remove excess DTT or glutaraldehyde, re-suspended in a buffer solution (pH 6.0) and incubated for 1 hour at room temperature. Finally the $\mathrm{CaCO}_{3}$ template was removed by addition of EDTA $(0.2 \mathrm{M})$ and incubated for 1 hour at room temperature. The resulting BSA-peroxidase microparticles were washed twice by centrifugation (4000 rpm, 2 minutes) and finally redispersed in $2 \mathrm{~mL}$ PBS at pH 6.0.

\subsection{Preparation of BSA-Gt $\alpha$ M IgG microparticles.}

A solution containing $0.5 \mathrm{~mL}$ calcium chloride $(1 \mathrm{M}), 400 \mu \mathrm{L} \mathrm{BSA}\left(20 \mathrm{mg} \mathrm{mL}^{-1}\right)$ and

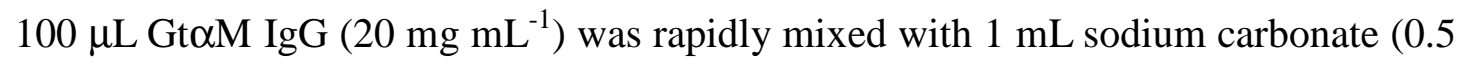
M) and keep stirring for 30 seconds to produce BSA/Gt $\alpha M$ IgG loaded $\mathrm{CaCO}_{3}$ microparticles. Afterward, the formation of the BSA-GtoM IgG microparticles followed the same procedures as the BSA-peroxidase microparticles.

\subsection{Preparation of multifunctional microparticles.}

A solution containing $0.5 \mathrm{~mL}$ calcium chloride $(1 \mathrm{M}), 360 \mu \mathrm{L}$ BSA $\left(20 \mathrm{mg} \mathrm{mL}^{-1}\right), 40$ $\mu \mathrm{L}$ BSA-HRP $\left(20 \mathrm{mg} \mathrm{mL}^{-1}\right)$ and $100 \mu \mathrm{L} \mathrm{Gt \alpha M} \mathrm{IgG}\left(20 \mathrm{mg} \mathrm{mL}^{-1}\right)$ was rapidly mixed with $1 \mathrm{~mL}$ sodium carbonate $(0.5 \mathrm{M})$ and keep stirring for 30 seconds to produce BSA/BSA-peroxidase/Gt $\alpha \mathrm{M}$ IgG loaded $\mathrm{CaCO} 3$ microparticles. Afterward, the formation of the BSA/BSA-peroxidase/GtoM IgG microparticles (multifunctional 
microparticles) followed the same procedures as the BSA-peroxidase microparticles.

\subsection{Preparation of Layer-by-Layer ( $\mathrm{LbL}$ ) modified peroxidase polystyrene (PS) microparticles.}

$10 \mu \mathrm{L}$ of PS microparticles with diameter of $2 \mu \mathrm{m}$ was collected from a stock solution and was dispersed in $2 \mathrm{~mL}$ of distilled water. The PS microparticles were then washed with distilled water for 3 times by repeated centrifugation and re-dispersion cycles at 4,000 r.p.m. for 2 minutes and finally resuspended in $0.5 \mathrm{M}$ sodium chloride $(\mathrm{NaCl})$ solution. The deposition of cationic polyelectrolyte (i.e. PAH) onto PS microparticles was achieved by incubating the PS microparticles with $2 \mathrm{~mL}$ of PAH solution $(5 \mathrm{mg}$ $\mathrm{mL}^{-1}$ in $0.5 \mathrm{M} \mathrm{NaCl}$ ) at room temperature for 15 minutes followed by removing the excess polyelectrolyte by three times washing and redispersion cycles by centrifugation (4,000 r.p.m. for 2 minutes). The deposition of second layer of anionic polyelectrolyte (i.e. PSS) was performed with similar procedures by incubating the PS microparticles with $2 \mathrm{~mL}$ of PSS solution $\left(5 \mathrm{mg} \mathrm{mL}^{-1}\right.$ in $\left.0.5 \mathrm{M} \mathrm{NaCl}\right)$. Alternating deposition of PAH and PSS was performed to produce five layer coated PS microparticles (i.e. [PAH/PSS $]_{4}$ PAH PS microparticles). Subsequently, the LbL modified PS microparticles were conjugated with peroxidase by incubating the microparticles with $2 \mathrm{~mL}$ peroxidase solution $\left(\sim 770\right.$ units $\left.\mathrm{mL}^{-1}\right)$ for 30 minutes at room temperature. The excess un-conjugated peroxidase were then removed by washing the PS microparticles by 5 times centrifugation and redisperion cycles $(4,000$ r.p.m. for 2 minutes). Finally, the resulting peroxidase PS microparticles were resuspended in PBS buffer (pH 7.0) for further experiments.

\subsection{Colorimetric Bead-based Enzymatic Bioassay.}

$40 \mu \mathrm{L}$ of $\mathrm{H}_{2} \mathrm{O}_{2}$ with concentrations ranged from 30 to $210 \mu \mathrm{M}$ was mixed with $40 \mu \mathrm{L}$ of SeramunBlau®prec reagent and $40 \mu \mathrm{L}$ of BSA-peroxidase microparticles. The BSA-peroxidase microparticles reaction mixture was then incubated at room temperature for 15 minutes. Subsequently, the colour intensity of the BSA-peroxidase microparticles were immediately examined by an optical microscope and recorded by digital camera.

\subsection{Fluorescence Bead-based Immunoassays.}

$40 \mu \mathrm{L}$ of $\mathrm{M} \mathrm{IgG}$ with concentrations ranged from 1.25 to $20 \mu \mathrm{g} \mathrm{L}^{-1}$ was mixed with 40 $\mu \mathrm{L}$ of BSA-Gt $\alpha \mathrm{M}$ IgG microparticles. The BSA-Gt $\alpha \mathrm{M}$ IgG microparticles reaction mixture was then incubated at room temperature for 15 minutes followed by five times washing with PBS ( $\mathrm{pH} 7.4$ ) to remove unbounded $\mathrm{M} \mathrm{IgG}$ and redispersed in 40 $\mu \mathrm{L}$ PBS (pH 7.4). Subsequently, $40 \mu \mathrm{L}$ of FITC- Gt $\alpha \mathrm{M}$ IgG solution was added to 
the BSA-GtoM IgG microparticles and was incubated for 15 minutes. Finally, the BSA-Gt $\alpha$ M IgG microparticles were washed five times with PBS ( $\mathrm{pH} 7.4)$ to remove excess FITC- Gt $\alpha \mathrm{M}$ IgG. The fluorescence intensity of the BSA-Gt $\alpha \mathrm{M}$ IgG microparticles were immediately examined by a fluorescent microscope and recorded by digital camera.

\subsection{Scanning Electron Microscopy (SEM).}

The surface morphologies of different samples were examined by Scanning Electron Microscopy (SEM). The samples were placed onto a copper stage followed by the deposition of a gold film. SEM images were recorded with JSM-6700F (JEOL, Japan).

\subsection{Optical Microscopy.}

Phase contrast and fluorescence microscopy images were recorded using a CCD color digital camera Spot-Insight QE (Diagnostic Instruments, Inc, USA) connected to a system microscope Olympus BX41 with a mercury arc (Olympus HBO103W/2) excitation source. Images were captured by a Spotsoftware (Version 4.6, Diagnostic Instruments, Inc, USA) and analyzed by ImageJ (National Institutes of Health, USA).

\subsection{Calculation on the number of peroxidase and antibody molecules in microparticle.}

The amount of protein molecules composing in each BSA-peroxidase particle was calculated to be $5.09 \times 10^{6}$ molecules based on the following equations: Number of protein molecules in the reaction mixture $=(m / M) E_{\text {trap }} N_{\mathrm{A}} / N_{N}$, where $m$ is the mass of protein molecules in the co-precipitation reaction mixture $(=10 \mathrm{mg}), M$ is the average molecular weight of protein molecules $\left(\sim 65,000 \mathrm{~g} \mathrm{~mol}^{-1}\right), E_{\text {trap }}$ is the protein entrapment efficiency measured by absorbance at $280 \mathrm{~nm}(\sim 55 \%), N_{\mathrm{A}}$ is the Avogadro number $\left(=6.02 \times 10^{23}\right)$ and $N_{N}$ is the total number of BSA-peroxidase particles $\left(\sim 1 \times 10^{10}\right)$. Since the percentage composition of the peroxidase in the BSA-peroxidase particle is $\sim 4 \%$, the number of peroxidase molecules composed in each BSA-peroxidase particle was calculated to be $\sim 2.04 \times 10^{5}$ molecules.

The amount of peroxidase molecules composing in each PS-peroxidase particle was calculated to be $\sim 5.76 \times 10^{4}$ molecules based on the following equations: Number of HRP molecule in each HRP-PS particles $=\left(A_{P S} \operatorname{Pro}_{S u r} / M\right) E_{a d s} N_{\mathrm{A}}$, where $A_{P S}$ is total surface area of the PS-peroxidase particle $\left(\sim 3.14 \times 10^{-12} \mathrm{~m}^{2}\right)$, Pro Sur $_{\text {in }}$ is the average theoretical surface coverage value of a protein monolayer $\left(\sim 3.6 \mathrm{mg} \mathrm{m}^{-2}\right)$ (Buijs et al., 1995; Nakamura et al., 1992), $M$ is the average molecular weight of protein molecules $\left(\sim 65,000 \mathrm{~g} \mathrm{~mol}^{-1}\right), E_{a d s}$ is the protein adsorption efficiency measured by absorbance at 
$280 \mathrm{~nm}(\sim 55 \%)$ and $N_{\mathrm{A}}$ is the Avogadro number $\left(=6.02 \times 10^{23}\right)$.

The amount of Gt $\alpha \mathrm{M}$ IgG molecules composing in each Gt $\alpha \mathrm{M}$ IgG-BSA particle was calculated to be $4.41 \times 10^{5}$ molecules based on the following equations: Number of Gt $\alpha \mathrm{M}$ IgG molecules in each Gt $\alpha \mathrm{M}$ IgG-BSA particle $=(m / M) E f f N_{\mathrm{A}} / N_{N}$, where $m$ is the mass of Gt $\alpha \mathrm{M}$ IgG molecules in the co-precipitation reaction mixture (=2 $\mathrm{mg}), M$ is the average molecular weight of protein molecules $\left(\sim 150,000 \mathrm{~g} \mathrm{~mol}^{-1}\right)$, Eff is the protein entrapment efficiency measured by absorbance at $280 \mathrm{~nm}(\sim 55 \%), N_{\mathrm{A}}$ is the Avogadro number $\left(=6.02 \times 10^{23}\right)$ and $N_{N}$ is the total number of Gt $\alpha$ M IgG-BSA particles $\left(\sim 1 \times 10^{10}\right)$.

\section{RESULTS AND DISCUSSION}

\subsection{Colorimetric bead-based enzymatic bioassays.}

Colorimetric bead-based enzymatic bioassays for hydrogen peroxide detections were performed using the developed protein particles and conventional polystyrene (PS) particles, respectively. Protein analytical particles composed of peroxidase and BSA molecules (BSA-peroxidase particles) were fabricated using the PASS method and the conventional PS analytical particles were constructed by conjugation of peroxidase molecules onto the surfaces of the PS particles (PS-peroxidase particles) via a Layer-by-Layer (LbL) method. The BSA-peroxidase particles and PS-peroxidase particles were incubated with a sample solution containing hydrogen peroxide and TMB substrate. The BSA-peroxidase particles convert the TMB into blue color precipitates that accumulate inside the protein particles resulted to the formation of blue color particles (Figure 2A). Moreover, a clear colourless background was observed suggesting the BSA-peroxidase particles were stable without leaking of enzymes into the bulk phase. In contrast, the colour of the PS-peroxidase particles remain unchanged, while blue color precipitates were freely suspended in the bulk phase solution (indicated by arrows) without attaching to the PS particle surfaces (Figure 2B). In addition, the analytical performance of the BSA-peroxidase particles and the PS-peroxidase particles were compared by applying approximately the same number of different types of particles $\left(\sim 10^{5}\right.$ particles per $\left.\mathrm{mL}\right)$ for individual measurements of hydrogen peroxide $(20 \mu \mathrm{M})$ in bulk phase followed by spectrophotometric detection at $650 \mathrm{~nm}$. The assay sensitivity, defines as the slope of the calibration curve, of the BSA-peroxidase particles showed a 4.7 times increase when compared to the PS-peroxidase particles (Figure S1). These results demonstrated the advantages of the BSA-peroxidase particle over the conventional PS particles as analytical platforms for enzymatic bioassays.

In order to understand the relationship between the amounts of peroxidase molecules composed in each particles and its signal increase, the number of peroxidase 
molecules in the BSA-peroxidase particles and PS-peroxidase particles was calculated (details refer to experiment section). The amount of peroxidase molecules composing in each BSA-peroxidase particle and PS particles was calculated to be $\sim 2.04 \times 10^{5}$ molecules and $\sim 5.76 \times 10^{4}$, respectively. From the above calculation, the amount of peroxidase molecules composed in the BSA-peroxidase particle is 3.6 times more compared to the PS-peroxidase particle. This calculated value is slightly lower than the experiment result of 4.7 times increase in assay sensitivity in the BSA-peroxidase particle system. The different in the calculated value and experimental value may due to partially protein degradation/denaturation occurred during the particle formation, and different in substrate diffusion rate in the BSA-peroxidase particle and PS-peroxidase particle.

However, it is important to notice that the percentage composition of the peroxidase in the BSA-peroxidase particle of the current system only accounted for $4 \%$, which can be further increased by increasing the percentage of peroxidase content. In contrast, the loading of peroxidase molecules using conventional Layer-by-Layer (LbL) method in the PS-peroxidase particle system is reaching its theoretical maximum capacity.

\section{Preferred position for Figure 2}

Conventional PS particles provide a two dimensional platform where bioassays are only performed on the particle surfaces. More than $98 \%$ of the entire volume of the PS-peroxidase particles is without any biological function and is almost wasted. PS particles are useful platforms for surface binding assays. However, PS particles lacking of an internal compartment are difficult to be applied for enzymatic bioassays. In contrast, protein particles have several distinct advantages over the conventional PS particles as bead-based analytical platforms. The protein particles are fully composed of protein molecules in the entire volume of the protein particles. It provides a three dimensional analytical platform for the performance of bioassay, and therefore, the effective area for bioassays per unit volume is significantly increased. In addition, the large internal volume allows a high enzyme loading within a single protein particle. The large surface-area-to-volume ratio and porous nature of the protein particles both facilitate effective analyte diffusion. Figure $\mathbf{3 A} \& \mathbf{B}$ shows the scanning electron micrographs of the BSA-peroxidase particles and PS-peroxidase particles, respectively. The BSA-peroxidase particle has a high density of pores structure while the PS-peroxidase particle has a smooth surface with few pores. The high density porous structure of the protein particles provides a site for the accumulation and localization of the enzymatic generated blue color precipitates. The unique features of 
the protein microparticles provide an ideal bead-based platform to perform enzymatic bioassays.

To understand the signal generation mechanism, BSA-peroxidase particles with and without the addition of hydrogen peroxide and TMB substrate (enzyme substrate) were examined by SEM (Figure 3 C-E) (insert shows the correlated colorimetric assay results of the BSA-peroxidase particle). The BSA-peroxidase particles originally appeared as a spherical shape with a smooth surface (Figure 3C). After the addition of hydrogen peroxide and TMB substrate for 10 minutes, an intense blue color was developed inside the BSA-peroxidase particles. However, there is no significant change on the surface morphology of the BSA-peroxidase particles (data not shown). We believe it is because the precipitates were masked by the surface of the BSA-peroxidase particles. In this context, we allow the enzymatic reaction to continue for sufficiently long time for 40 minutes. Figure 3D and 3E show the SEM images of a BSA-peroxidase particle with a partially ruptured structure and an intact BSA-peroxidase particle, respectively. The partially ruptured BSA-peroxidase particles allow the examination of the interface between the protein particle surface and the precipitates. Needle-like precipitates were grown from the pores of the BSA-peroxidase particles surface (indicated by arrows) and finally wrapping around the BSA-peroxidase particles. These results demonstrated the advantages of the protein particles to serve as a bead-based platform for enzymatic bioassays.

\section{Preferred position for Figure 3}

\subsection{Quantitative coloriometric bead-based enzyme bioassays for hydrogen peroxide detection.}

Enzymatic bioassays for quantitative detection of hydrogen peroxide with a concentration ranged from 10 to $70 \mu \mathrm{M}$ were performed using the BSA-peroxidase microparticles. Images of the BSA-peroxidase particles after addition of various amount of hydrogen peroxide were recorded by digital camera attached on an optical microscope. An elevated blue colour intensity was observed as the hydrogen peroxide concentration increased (Figure 4A). The lowest blue colour intensity that can be determined with naked eyes was found to be $10 \mu \mathrm{M}$ hydrogen peroxide. In addition, the colour intensity of the BSA-peroxidase particles were quantified by measuring the average pixel intensity per unit area of individual particle with an imaging software (ImageJ, National Institutes of Health, USA). The relative color intensity was defined as the percentage increase in the blue color intensity compared to the blank BSA-peroxide particle without the addition of an analyte. For each measurement, a number of 30 particles were analyzed and the mean value of the optical density was 
calculated. The relative color intensities of the BSA-peroxidase microparticles were directly proportional to the amount of hydrogen peroxide present in the sample (Figure 4B). The assay sensitivity which is defined as the relative percentage of signal intensity increase per unit change of hydrogen peroxide concentration $(\mu \mathrm{M})$ was calculated to be 1.47 with $\mathrm{R}^{2}$ of 0.98 .

Convention optical detection of hydrogen peroxide have been developed based on enzymatic catalyzed reaction generating optical active species followed by detection using spectrophotometric, fluorometric or chemiluminescence techniques. Examples are including peroxidase catalyzed colorimetric lateral flow assay with TMB substrate with detection limit of $1.25 \mu \mathrm{M} \mathrm{H}_{2} \mathrm{O}_{2}$ (Fung et al., 2009); fluorometric assay with Amplex Red® substrate with detection limit of 5 pmol $\mathrm{H}_{2} \mathrm{O}_{2}$ (Rhee et al., 2010); and chemiluminescence membrane assay with sodium luminol substrate with detection limit of 25 pmol $\mathrm{H}_{2} \mathrm{O}_{2}$ (Rubtsova et al., 1997). The sensitive of the peroxidase catalyzed bioassays mainly determined by the extinction coefficients of the enzyme substrate. The sensitivity of the BSA-peroxidase particle detection system may improve by choosing a proper fluorometric or chemiluminescence peroxidase substrate.

Besides substrate selection, one of the critical parameters influences the sensitive and detection limit of enzymatic optical bioassays for hydrogen peroxide measurement is depends on the detection method in combination with the sensitivity of the analytical instrument. Instead of analyzing individual BSA-peroxidase particle with a digital camera and an optical microscope, the analytical performance of the BSA-peroxidase particle detection system can be improved by measuring the color intensity with a spectrophotometer (Figure S1). The lowest detectable hydrogen peroxide concentration analysis by spectrophotometric measurement is $500 \mathrm{nM}$ which is 20 times more sensitive compared to microscope measurement. In addition, measurements performed by using spectrophotometric technique only required an assay incubation time of 10 minutes while using microscopic digital imaging technique required an assay incubation time of 15 minutes. This can be explained by the fact that the optical sensitivity of spectrophotometric system is better than the microscopic digital imaging system.

\section{Preferred position for Figure 4}

\subsection{Fluorescence bead-based immunoassays.}

In order to perform bead-based fluorescence bioassays, the particles platform is required to be fluorescent inactive. Fabrication of protein particles based on conventional chemical crosslink reagents such as glutaraldehyde by reactions of its 
two aldehyde moieties with protein amino groups will give rise to the formation of auto-fluorescent reaction complexes (Fester et al. 2008). In addition, auto-fluorescence problem also appeared on the most commonly used particle surface modification technique (LbL technique) using polyelectrolyte such as PSS and PAH (Meyer et al., 2008). Our developed protein particle fabrication technology using PASS overcomes the auto-fluorescence problem by self-assembling protein molecules into particles via naturally occurring protein-protein interaction (i.e. cysteine-cysteine interaction). Protein particles fabricated using PASS technology gave non-fluorescence signal in the visible region from $455 \mathrm{~nm}$ to $580 \mathrm{~nm}$; while protein particles fabricated using glutaraldehyde crosslink method showed strong auto-fluorescence signals (Figure S2). This is a significant development towards the application of protein particles for fluorescence bioassays.

\subsection{Quantitative fluorescence bead-based immunoassays for M IgG detection.}

Sandwich immunoassays for quantitative detection of $\mathrm{M}$ IgG with a concentration ranged from 1.25 to $20 \mu \mathrm{g} \mathrm{L}^{-1}$ were performed using the BSA-Gt $\alpha \mathrm{M}$ IgG particles. An increased fluorescence signal was observed under fluorescence microscope as the $\mathrm{M}$ IgG concentration increased (Figure 5A). Quantitative results can be obtained by evaluating the relative fluorescence intensity of individual BSA-Gt $\alpha$ M IgG particles with an imaging software (ImageJ, National Institutes of Health, USA). The relative fluorescence intensity was defined as the percentage increase in the fluorescence intensity compared to the blank BSA-Gt $\alpha \mathrm{M}$ IgG particle without the addition of an analyte. For each measurement, a number of 30 particles were analyzed and the mean value of the fluorescence intensity was calculated. The relative fluorescence intensity is directly proportional to the amount of M IgG present in the sample (Figure 5B). The assay sensitivity which is defined as the relative percentage of fluorescence intensity increase per unit change of $\mathrm{M} \operatorname{IgG}$ concentration $\left(\mu \mathrm{g} \mathrm{L}^{-1}\right)$ was calculated to be 3.61 with $\mathrm{R}^{2}$ of 0.98 .

Conventional bead-based immunoassays were mainly performed using microparticles with immobilized antibodies on the particle surface. Examples are including fluorescence agarose bead-based immunoassay for detection of C-reactive protein (CRP) with detection limit of $1 \mu \mathrm{g} \mathrm{L}^{-1}$ (Du et al., 2011); fluorescence bead-based FlowMetrix @ flow cytometry immunoassays (Luminex) for detection of human cytokines with sensitivity of $10 \mathrm{ng} \mathrm{L}^{-1}$ (Kellar et al., 2001); and fluorescence bead-based AlphaLISA ${ }^{\circledR}$ flow cytometry immunoassays (PerkinElmer) for detection of angiotensin I (Ang I) in plasma with detection limit of $0.2 \mathrm{pg} \mathrm{L-1} \mathrm{Ang} \mathrm{I} \mathrm{per} \mathrm{hour}$ (Cauchona et al., 2009). According to literature, the sensitive of BSA-GtoM IgG particle immunoassays may improve by detection using flow cytometry technique. 


\section{Preferred position for Figure 5}

\subsection{Multifunctional protein particles for enzymatic bioassays and immunoassays with colorimetric and fluorescence channels.}

Protein particles composed of BSA, peroxidase and Gt $\alpha$ M IgG (multifunctional protein particles) was used to demonstrate the concept of multifunctional bead-based analytical platforms. Our unique method to produce optically transparent and fluorescence inactive protein particles is the key to achieve multiplex bioassays with different optical channels. A colorimetric channel was assigned for the enzymatic bioassay for the detection of hydrogen peroxide and a fluorescence channel was assigned for the sandwich immunoassay for the detection of M IgG. In the presence of hydrogen peroxide or $\mathrm{M} \operatorname{IgG}$, the multifunctional protein particles generated only a blue color signal (Figure 6A) or a fluorescence signal (Figure 6B), respectively; while in the presence of both hydrogen peroxide and $\mathrm{M} \mathrm{IgG}$, the multifunctional protein particles generated both the blue color and fluorescence signal (Figure 6C). Larger populations of multifunctional protein particles with low magnification images were showed in Figure S3. It was observed that the signal intensities of the dual blue color and fluorescence channels for mixed hydrogen peroxide and $\mathrm{M}$ IgG measurements were similar to the signal intensity of the individual blue color channel and the fluorescence channel obtained by separate measurements of hydrogen peroxide and $\mathrm{M}$ IgG. This suggests the blue color signals generated by the enzymatic bioassays and the fluorescence signal generated by the sandwich immunoassays do not interfere to each other. Besides, the maximum absorption and excitation wavelength of FITC is at $495 \mathrm{~nm}$ and $520 \mathrm{~nm}$, respectively. While the maximum absorption wavelengths of the blue colour enzymatic product are at $370 \mathrm{~nm}$ and 630 $\mathrm{nm}$. The maximum absorption wavelengths of the blue colour enzymatic product are neither close to the maximum absorption of FITC nor the maximum emission of FITC (i.e. with a wavelength different of more than $100 \mathrm{~nm}$ ). Therefore, the effect of interference between FITC and the blue colour enzymatic product was minimized.

In general, multifunctional protein particles fabrication with the PASS method is simple and robust. The size of the resulted protein particles can be tailored by the controlling calcium carbonate co-precipitation process. The size distribution of the multifunctional protein particles measured by particle size analyzer (ZetaPlus, Brookhaven Instrument Corporation, USA) was $\sim 2.17 \mu \mathrm{m}$ with polydispersity of 0.045 (Figure S4). The stability of the BSA-peroxidase particles and BSA-Gt $\alpha$ M IgG particles was investigated. The enzymatic activity of the BSA-peroxidase particles remain $\sim 50 \%$ of the initiate value and the immuno activity of the BSA-GtoM IgG 
particles remain $\sim 70 \%$ of the initiate value after one week storage in PBS buffer $\mathrm{pH}$ 7.4 at room temperature (Figure S5). The decrease in activities may result from denaturation of the protein molecules during storage. Reservation of protein activities by storage at stabilization buffer may improve the stability of protein particles.

In order to study the performance of the protein particles for real sample measurement, we have performed the measurement of hydrogen peroxide and $\mathrm{M} \operatorname{IgG}$ in artificial serum sample according to method described by Ralloff $\mathrm{K}$ et.al., 2003. In brief, artificial serum composed of $120 \mathrm{mmol}^{-1} \mathrm{NaCl}, 20 \mathrm{mmol}^{-1} \mathrm{NaHCO}_{3}$ and $60 \mathrm{gL}^{-1} \mathrm{BSA}$ were used as sample matrix. Standard hydrogen peroxide solution or standard M IgG solution were spiked to the artificial serum matrix, followed by performing the bioassays with the BSA-peroxidase particles and BSA-GtoM IgG particle, respectively (Figure S6). The hydrogen peroxide assays and the M IgG assays for spiked artificial serum samples showed a decreased sensitivity of $26.7 \%$ and $39.4 \%$, respectively. The decrease in sensitivity may result from the diffusion barrier created by the serum matrix which reduces the diffusion rate of the substrates and analytes. In addition, the sensitivity drop is more significant for the M IgG assays which may due to the high molecular weight of the M IgG analyte.

Protein particles are promising new generation analytical platform. The results represented in this study demonstrate an innovative approach to perform enzymatic bioassays and immunoassays within a single particle analytical platform with dual colorimetric and fluorescence channels.

\section{Preferred position for Figure 6}

\section{CONCLUSIONS}

The applications of multifunctional protein microparticles for enzymatic bioassays and immunoassays with colorimetric and fluorescence channels have been demonstrated. A colorimetric channel based on coloured-substrate precipitation was assigned for the enzymatic bioassays for the detection of hydrogen peroxide and a fluorescence channel based on fluorescence labeled antibodies was assigned for sandwich immunoassays for the detection of $\mathrm{M}$ IgG. The substrate precipitation mechanism of the enzymatic bioassays within protein particles was characterized by SEM. Our results demonstrate the first time in literature the performance of enzymatic bioassay and immunoassay within a single particle platform. The multifunctional protein microparticles have many advantageous properties, such as high loading of analytical biomolecules, porous structure, being optically transparent and fluorescence inactive. These properties make our protein particle a new generation analytical platform to perform enzymatic assays and immunoassays. These findings are the 
foundation for further development of multifunctional protein analytical particles to a powerful multiplexing method for diagnostics and drug screening. The protein microparticles can be potentially integrated with existing micro-fluidic and lab-on-a-chip systems to develop a powerful tool for high throughput diagnostic, environmental and screening applications.

\section{REFERENCES}

Bai, J.H., Beyer, S., Mak, W.C., Rajagopalan, R., Trau, D., 2010. Angewandte Chemie-International Edition 49, 5189-5193.

Buijs, J., Lichtenbelt, W.T., Norde, W., Lyklema, J., 1995. J. Colloids Surf. B 5, 11-23.

Caruso, F., Trau, D., Mohwald, H., Renneberg, R., 2000. Langmuir 16, 1485-1488.

Cauchona, E., Liub, S., Percivala, M.D., Rowlandb, S.E., Xub, D., Binkertc, C., Stricknerc, P., Falgueyreta, J.P., 2009. Analytical Biochemistry 388(1), 134-139.

Du, N., Chou, J., Kulla, E., Floriano, P.N., Christodoulides, N., McDevitt, J.T., 2011. Biosensors \& Bioelectronics 28, 251-256.

Fester, T., Berg, R.H., Taylor, C.G., 2008. Journal of Microscopy 231, 342-348.

Fischer, T., Agarwal, A., Hess, H., 2009. Nature Nanotechnology 4(3), 162-166.

Fung, K.K., Chan, C.P.Y., Renneberg, R., 2009. Analytica Chimica Acta 634, 89-95.

Kasturi, S.P., Sachaphibulkij, K., Roy, K., 2005. Biomaterials 26, 6375-6385.

Kellar, K.L., Kalwar, R.R., Dubois, K.A., Crouse, D., Chafin, W.D., Kane, B.E., 2001. Cytometry 45, 27-36.

Kim, Y.H., Park, D., Hwang, J., Kim, Y.J., 2008. Lap chip 8, 1950-1956.

Mak, W.C., Bai, J., Chang, X.Y., Trau, D., 2009. Langmuir 25, 769-775.

Mak, W.C., Cheung, K.Y., Trau, D., 2008. Advanced Functional Materials 18(19), 2930-2937.

Mak, W.C., Cheung, K.Y., Trau, D., 2008. Chemistry of Materials 20, 5475-5484.

Mak, W.C., Cheung, K.Y., Trau, D., Warsinke, A., Scheller, F., Renneberg, R., 2005. Anal. Chem. 77, 2835-2841.

Mak, W.C., Georgieva, R., Renneberg, R., Bäumler, H., 2010. Advanced Functional Materials 20, 4139-4144.

Mak, W.C., Sin, K.K., Chan, C.P.Y., Wong, L.W., Renneberg, R., 2011. Biosensors \& Bioelectronics 26, 3148-3153.

Malmstadt, N., Hoffman, A.S., Stayton, P.S., 2004. Lab on a Chip 4, 412-415.

Meyer, S., Pescador, P., Donath, E., 2008. Journal of Physical Chemistry C 112, 1427-1434.

Nakamura, M., Ohshima, H., Kondo, T., 1992. J. Colloid Inferface Sci. 149, 241-246.

Parthasrathy, R.V., Martin, C.R., 1994. Nature 369, 298-301. 
Ralloff, K.P.G., Westh, P., Purssell, R.A., Pudek, M., Koga, Y., 2003. Fluid Phase Equilibria 207, 301-317.

Ramon-Azcon, J., Kunikata, R., Sanchez, F.J., Marco, M.P., Shiku, H., Yasukawa, T., Matsue, T., 2009. Biosensors \& Bioelectronics 24, 1592-1597.

Rhee, S.G., Chang, T.S., Jeong, W., Kang, D., 2010. Mol. Cells 29, 539-549.

Rubtsova, M.Y., Kovba, G.V., Egorov, A.M., 1977. Biosensors \& Bioelectronics 13, 75-85.

Verpoorte, E., 2003. Lab on a Chip 3, 60N-68N.

Vignali, D.A.A., 2000. Journal of Immunological Methods 243, 243-255.

Xiang, D.S., Zeng, G.P., He, Z.K., 2011. Biosensors \& Bioelectronics 26, 4405-4401.

Xu, Q., Hashimoto, M., Dang, T.T., Hoare, T., Kohane, D.S., Whitesides, G.M., Langer, R., Anderson, D.G., 2009. Small 13, 1575-1581.

Yan, X.M., Zhong, W.W., Tang, A.J., Schielke, E.G., Hang, W., Nolan, J.P., 2005. Anal. Chem 77, 7673-7678.

Yang, W.J., Trau, D., Renneberg, R., Yu, N.T., Caruso, F., 2001. Journal of Colloid and Interface Science 234, 356-362.

Zhang, Y.W., Liu, S., Sun, X.P., 2011. Biosensors \& Bioelectronics 26, 3876-3880. 


\section{FIGURE CAPTIONS}

Figure 1. Schematic diagram illustrating the multiplexed assay detection by multifunctional protein particle. Multifunctional protein particles composed of enzymes and antibodies were fabricated using a "Protein Activation and Spontaneous Self-assembly" approach. (A) In enzymatic bioassay, the analyte substrates are converted by enzymes inside the particle to coloured products for colorimetric detection. (B) For sandwich immunoassay, target antigens are captured by antibodies in the particle. After subsequent incubation with fluorescence-labelled detector antibodies, the particle showed a detectable fluorescence signal. (C) In the presence of both analyte substrates and target antigens, the multifunctional protein particle is capable to produce non-interfering signal in both colorimetric and fluorescence channel.

Figure 2. Optical micrographs of (A) BSA-peroxidase particles and (B) PS-peroxidase particles before and after addition of TMB substrate and hydrogen peroxide. The BSA-peroxidase particles showed an intense blue colour. While for PS-peroxidase particles, the blue precipitates formed were detached from the particle surfaces (indicates by arrows).

Figure 3. Scanning electron micrographs showing surface porosities of (A) BSA-peroxidase particles with arrows indicate the pore structure and (B) PS-peroxidase particles with a 150,000X magnification. Scanning electron micrographs showing the surface morphologies of BSA-peroxidase particles (C) before and (D) \& (E) after the addition of TMB substrate and hydrogen peroxidise (insert shows the correlated colorimetric assay results of the BSA-peroxidase particle).

Figure 4. (A) Optical micrographs of BSA-peroxidase particles showing different blue colour intensities correspond to the addition of hydrogen peroxide in various concentrations. (B) A graph showing the percentage increase in blue colour intensity against blank signal as a function of hydrogen peroxide concentration.

Figure 5. (A) Fluorescence micrographs of BSA-GtoM IgG particles showing different fluorescence intensities with respect to increasing $\mathrm{M} \operatorname{IgG}$ concentration. (B) A graph showing the relative fluorescence intensity as a function of $\mathrm{M} \operatorname{IgG}$ concentration.

Figure 6. Fluorescence micrographs (top) and corresponding optical micrographs 
(bottom) of multifunctional protein particles showing multiplexed detection in the presence of (A) hydrogen peroxide $(40 \mu \mathrm{M})$, (B) $\mathrm{M} \mathrm{IgG}\left(5 \mu \mathrm{g} \mathrm{L}^{-1}\right)$, and (C) both hydrogen peroxide $(40 \mu \mathrm{M})$ and $\mathrm{M} \operatorname{IgG}\left(5 \mu \mathrm{g} \mathrm{L}^{-1}\right)$.

Figure S1. Calibration curves comparing the performance of BSA-peroxidase particles (upper curve) and PS-peroxidase particles (lower curve) with spectrophotometric detection method. There are four repeated measurements for each data point.

Figure S2. Phase contrast micrographs and corresponding fluorescence micrographs of (A) dithiothreitol (DTT) crosslinked BSA-peroxidase particles and (B) glutaraldehyde crosslinked particles excited by different wavelengths.

Figure S3. Fluorescence micrographs (top) and corresponding optical micrographs (bottom) with low magnification showing a larger population of multifunctional protein particles for multiplex detection of (A) hydrogen peroxide $(40 \mu \mathrm{M})$, (B) $\mathrm{M}$ $\operatorname{IgG}\left(5 \mu \mathrm{g} \mathrm{L}^{-1}\right)$, and $(\mathrm{C})$ both hydrogen peroxide $(40 \mu \mathrm{M})$ and $\mathrm{M} \operatorname{IgG}\left(5 \mu \mathrm{g} \mathrm{L}^{-1}\right)$.

Figure S4. Particle size distribution curve of protein particles prepared by the protein activation spontaneous self-assembly (PASS) method.

Figure S5. Stability studies of (A) BSA-peroxidase particles and (B) GtoM IgG particles as a function of time. There are four repeated measurements for each data point.

Figure S6. Performance of (A) BSA-peroxidase particles and (B) Gt $\alpha \mathrm{M}$ IgG particles for measurement of hydrogen peroxide and $\mathrm{M}$ IgG in aqueous samples (upper curve) and artificial serum samples (lower curve), respectively. There are four repeated measurements for each data point. 
Figure 1

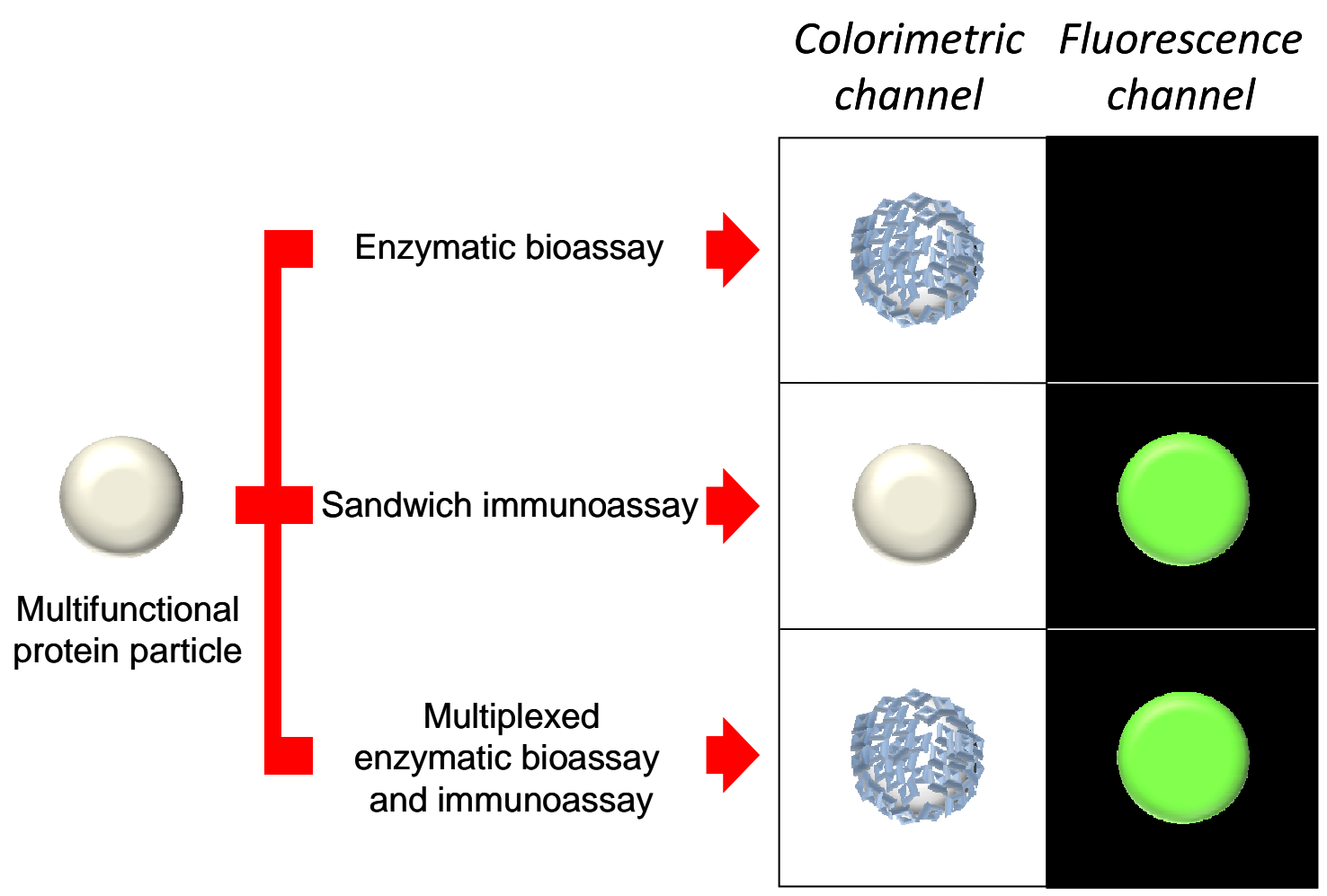


Figure 2
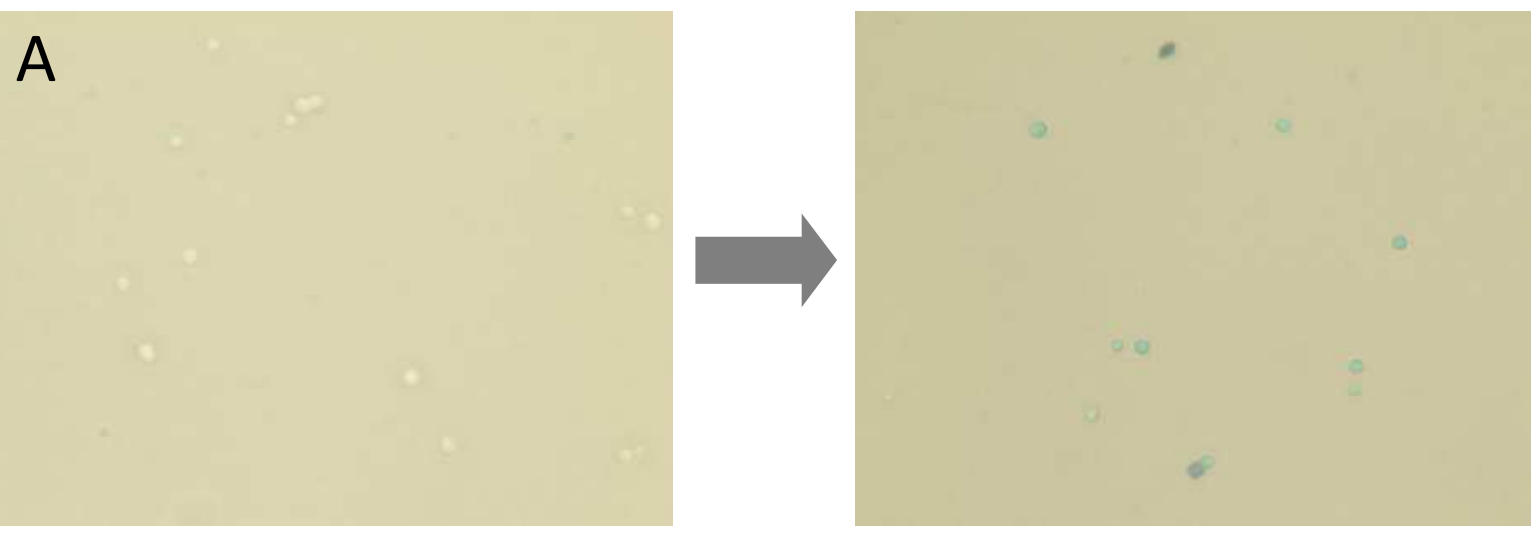

B
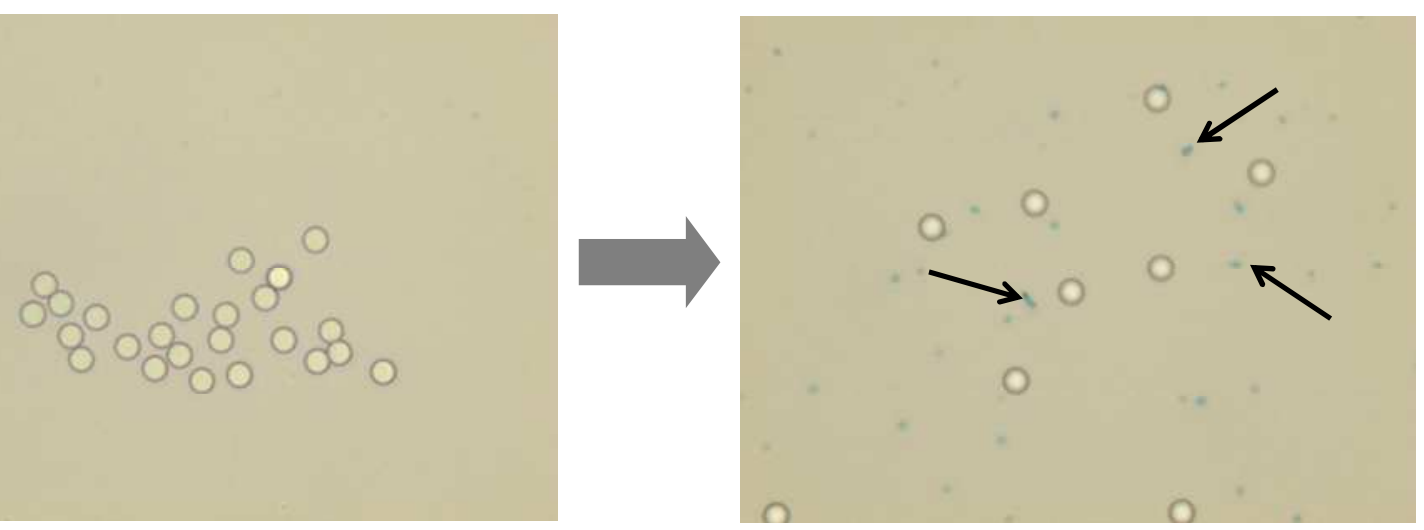
Figure 3
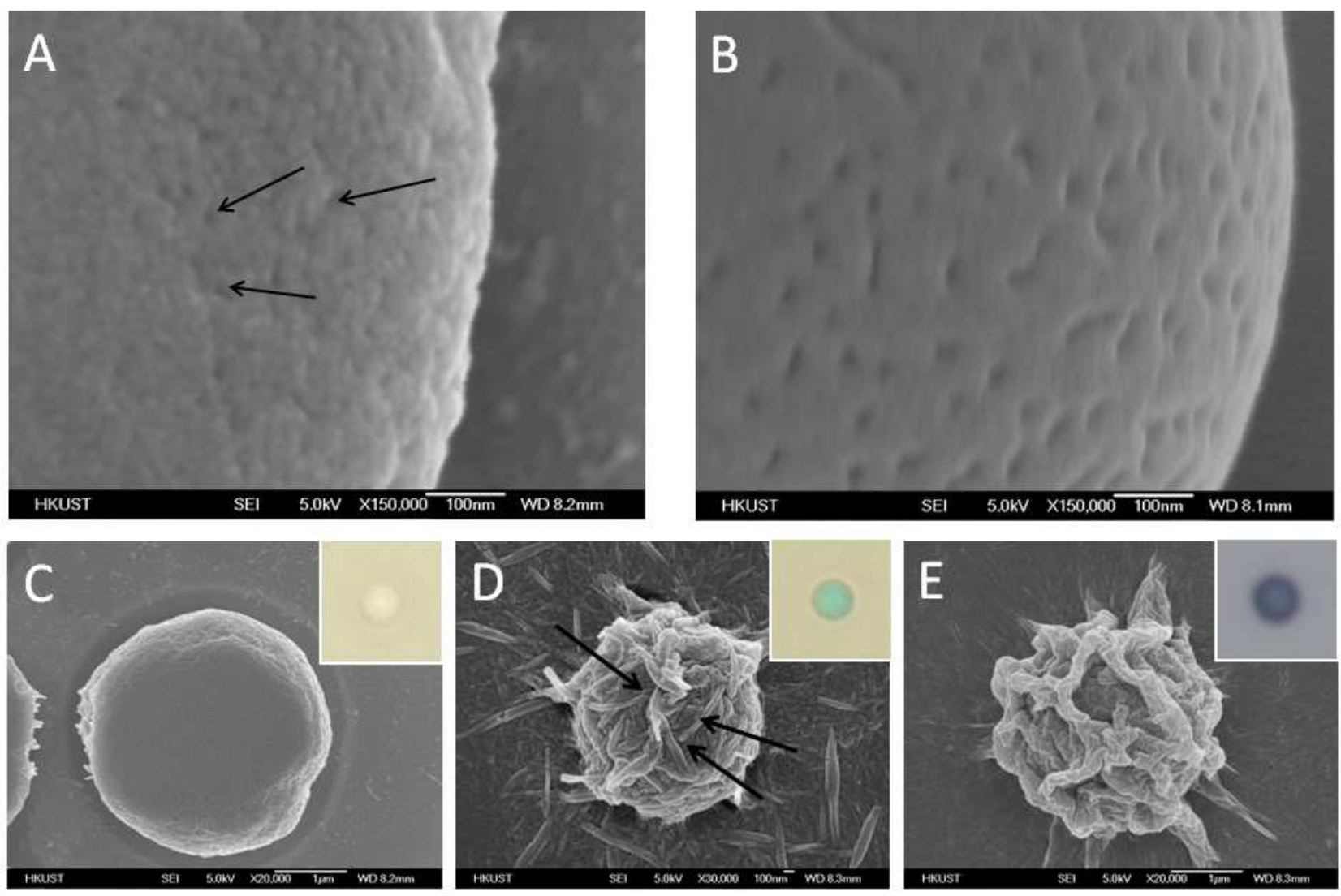
Figure 4

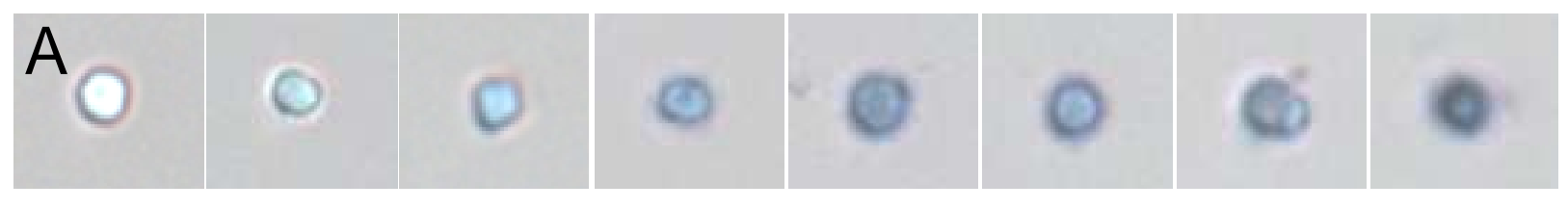

Control $\quad 10 \mu \mathrm{M} \quad 20 \mu \mathrm{M} \quad 30 \mu \mathrm{M} \quad 40 \mu \mathrm{M} \quad 50 \mu \mathrm{M} \quad 60 \mu \mathrm{M} \quad 70 \mu \mathrm{M}$

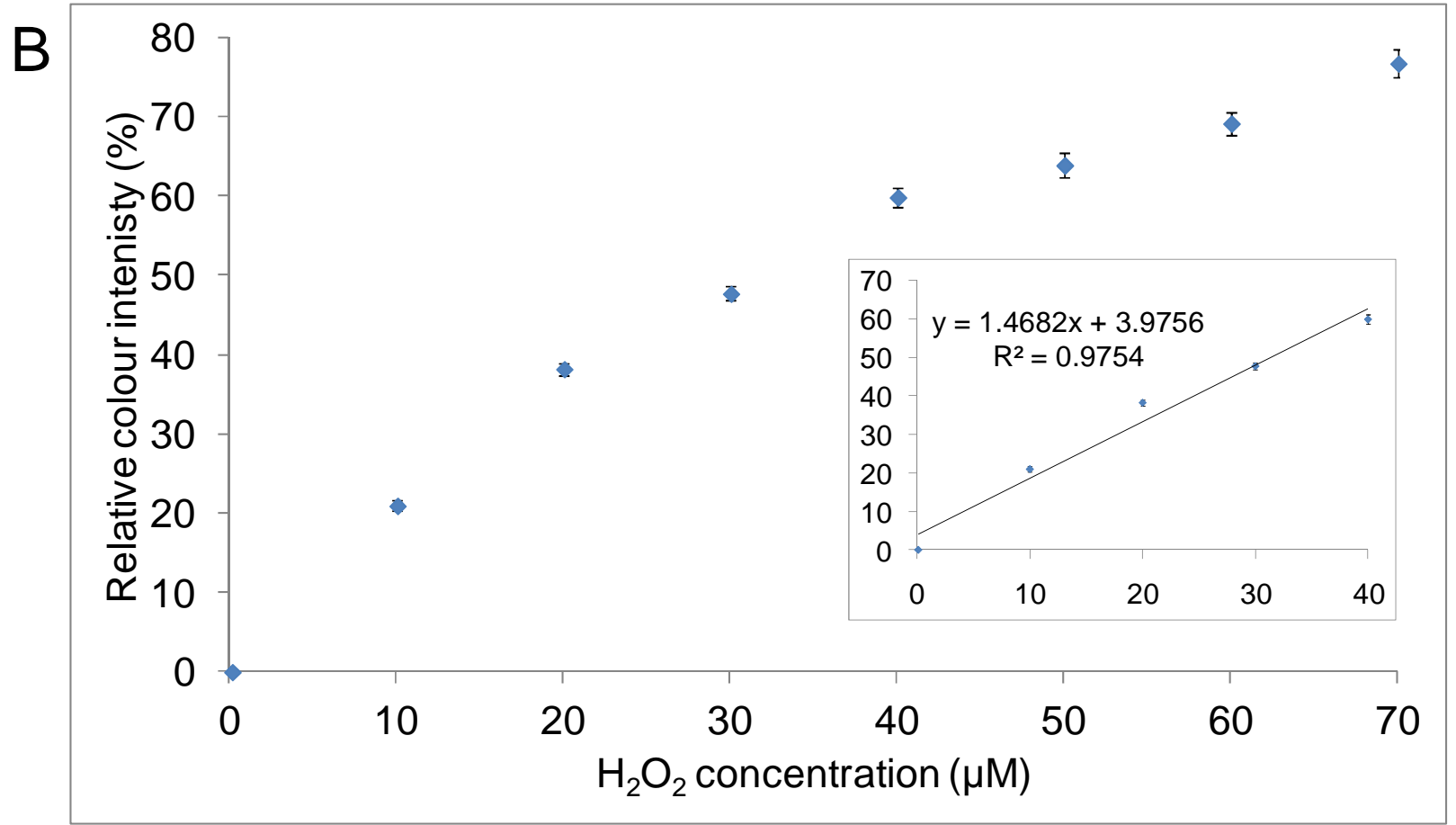


Figure 5

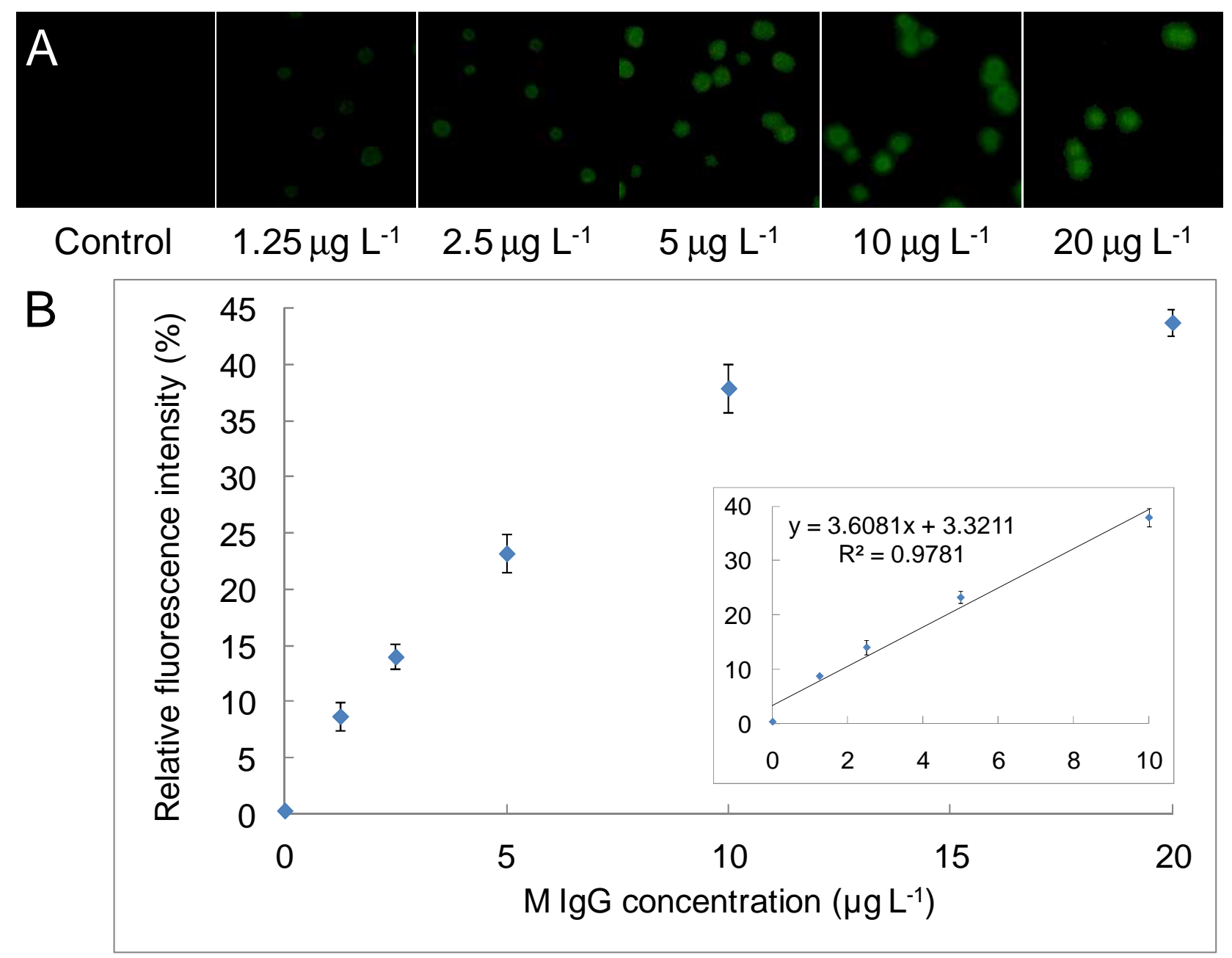


Figure 6

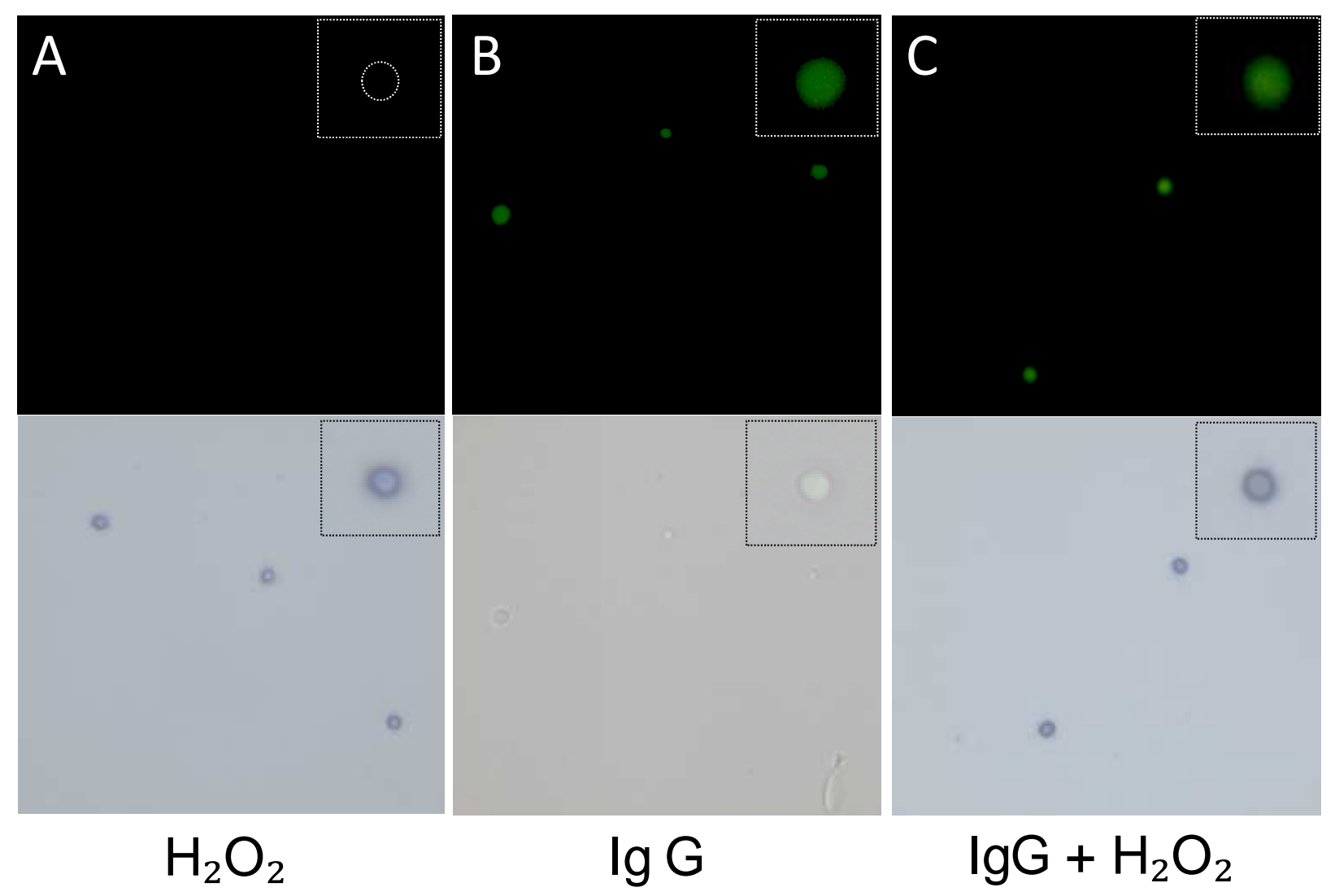


Figure S1

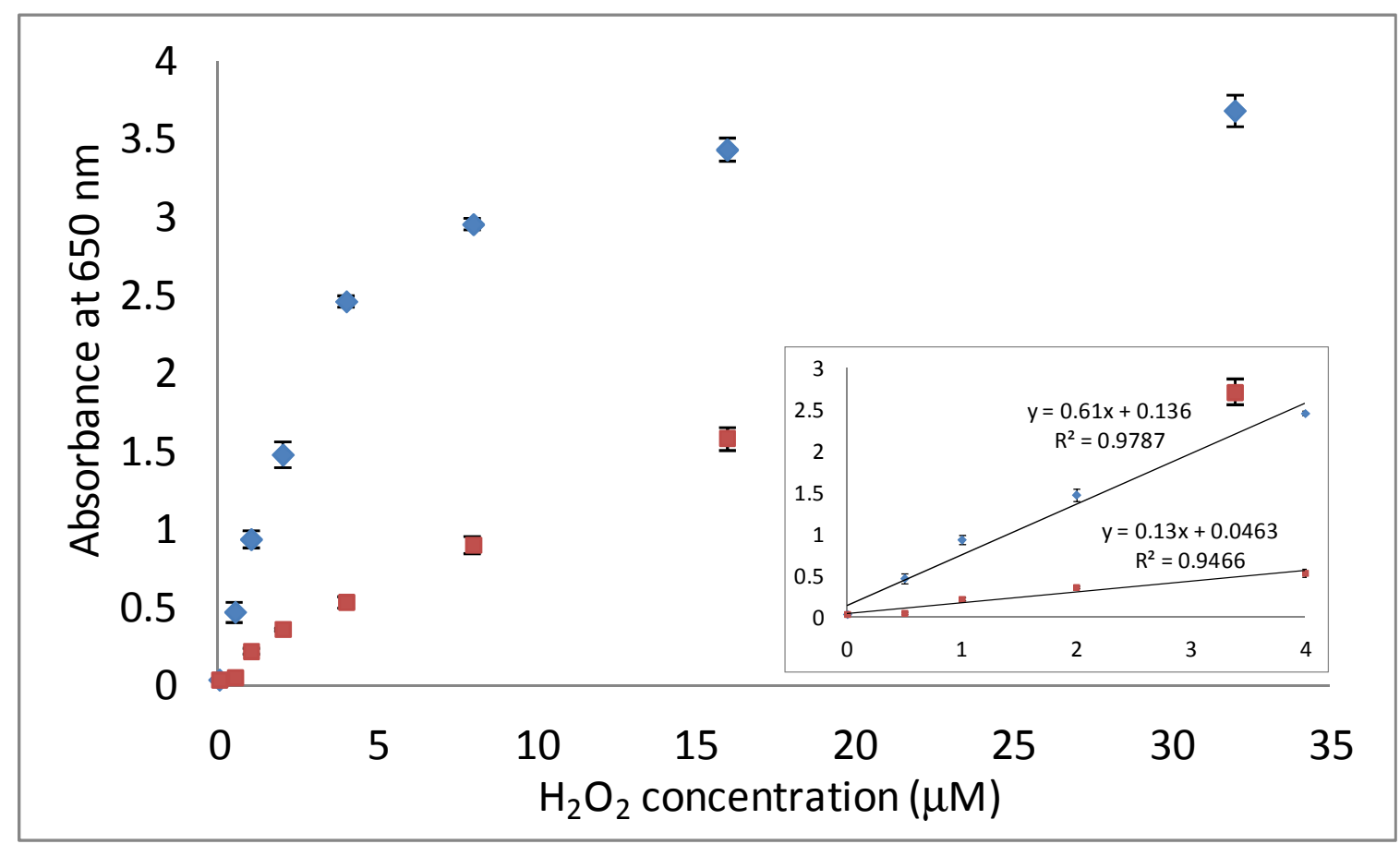


Figure S2

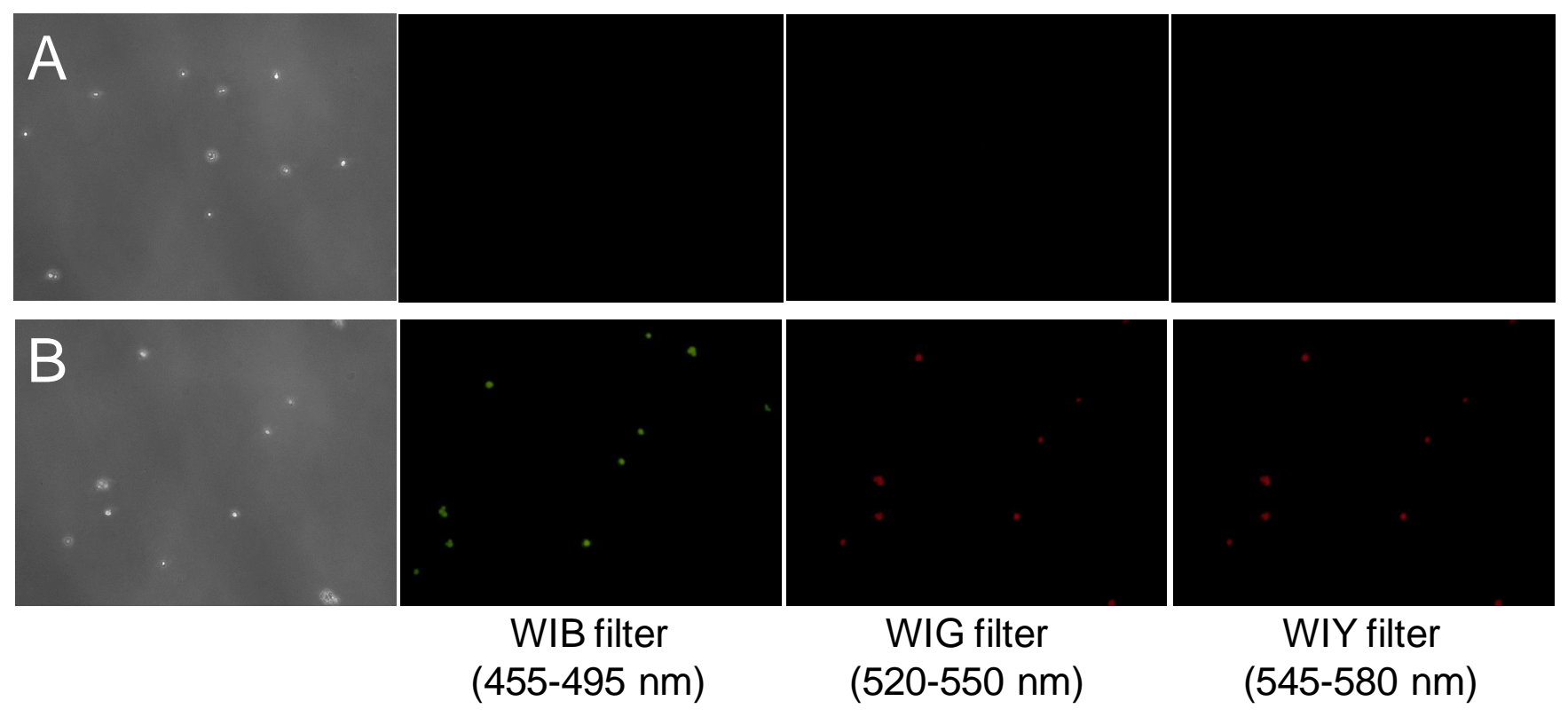


Figure S3

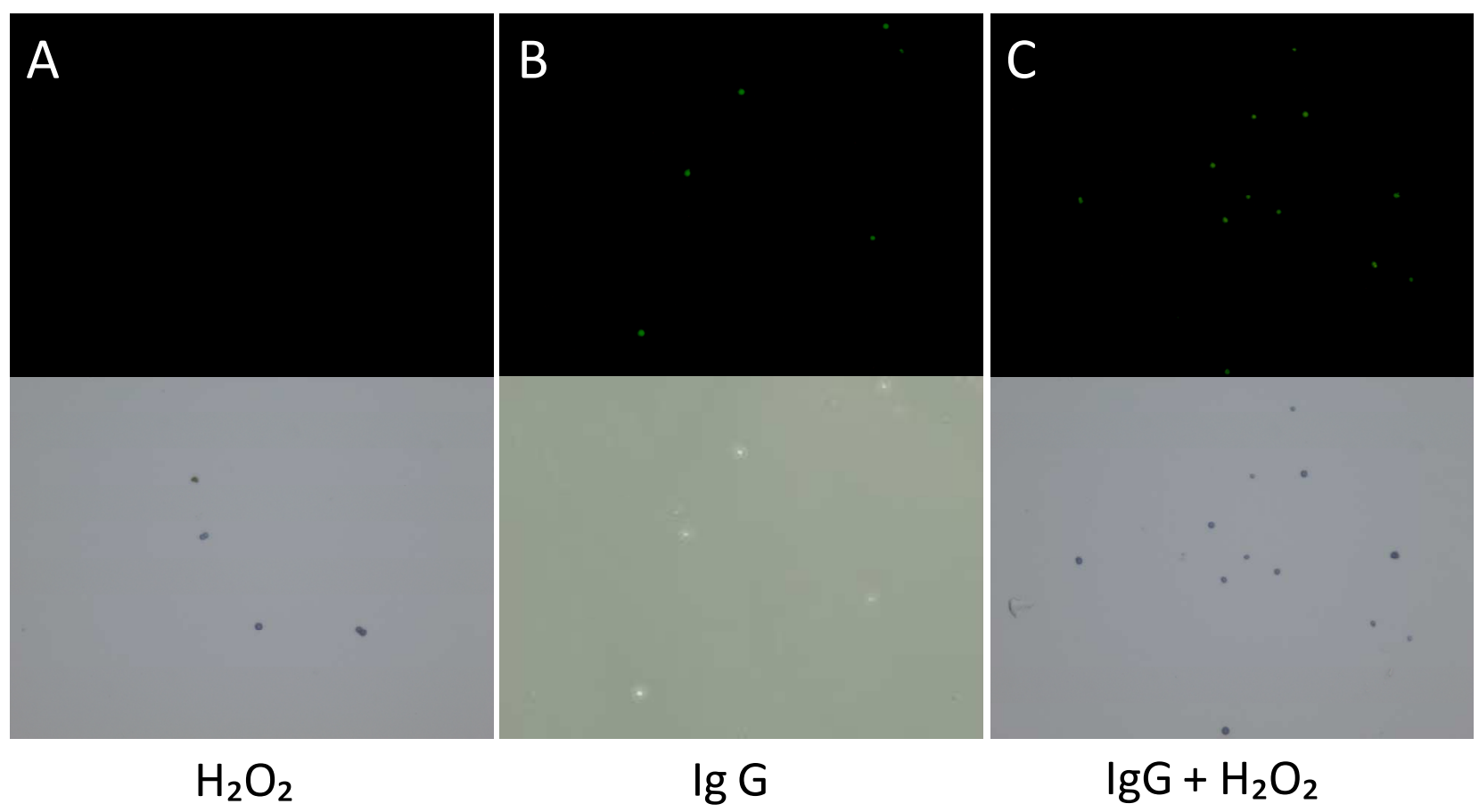


Figure S4

speed 0 (Combined)

Effective Diameter: $2170.1 \mathrm{~nm}$

Polydispersity: $\quad 0.045$

Avg. Count Rate: $\quad 439.0$ kcps

Baseline Index: $\quad 9.3$

Elapsed Time:

$00: 02: 30$

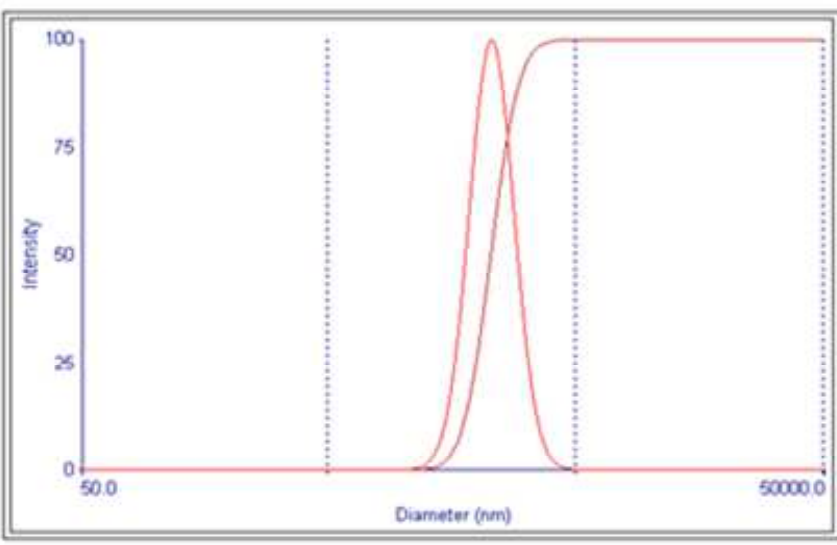


Figure S5
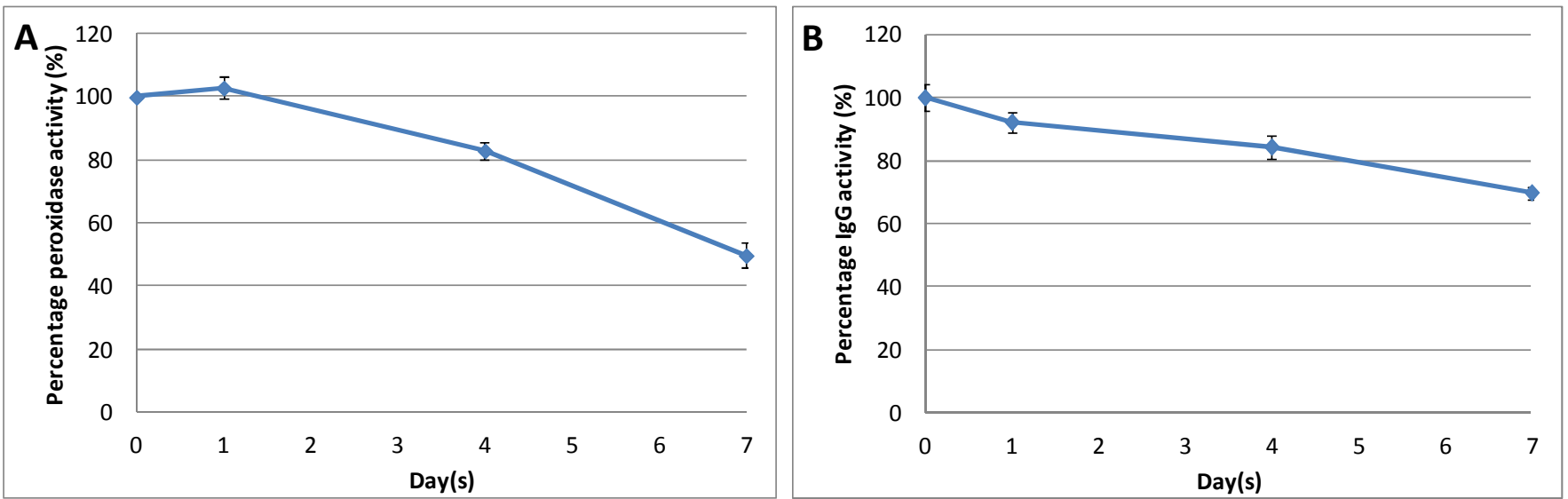
Figure S6
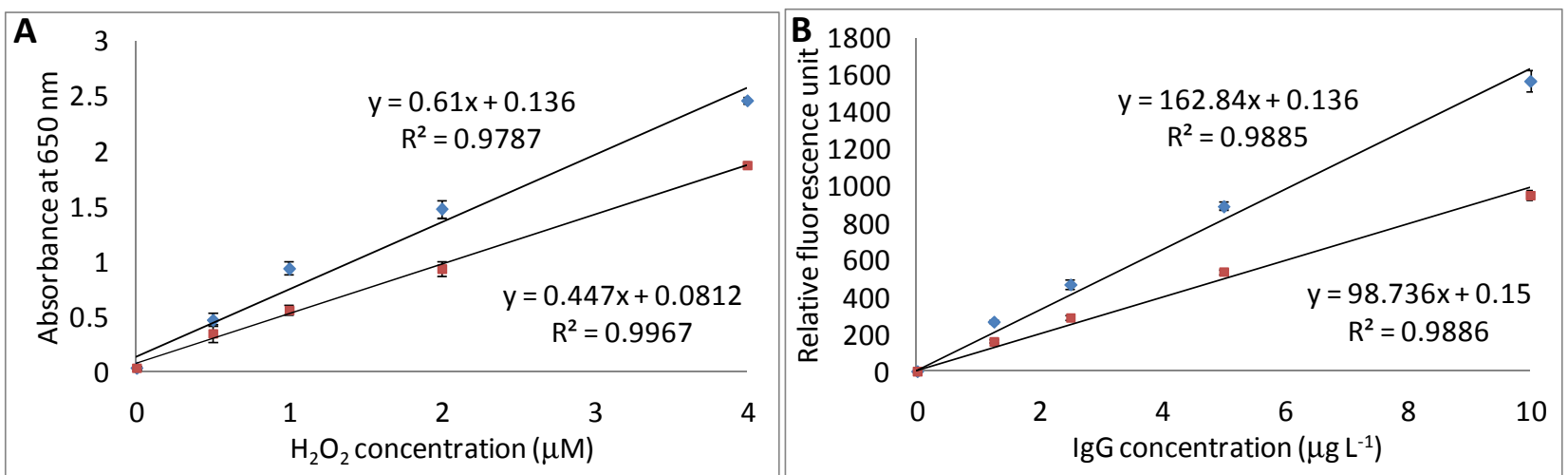